iMedPub Journals

http://journals.imed.pub

Vol. 7 No. 1:1 doi: $10.3823 / 0801$

\section{Prevalence and antibiotic susceptibility of ear pathogenic isolated from patients in Tripoli, north of Lebanon}

\section{Abstract}

Background: Ear infection is one of the most widespread illness usually caused by bacteria or viruses, and which can be extremely painful. They are the most common reason for parents to bring their children to clinicians. The aim of this study is to determine the prevalence and antibiotic susceptibility pattern of common bacterial ear pathogens isolated from patients in Tripoli, North Lebanon during the period of 7 years.

Methods: A total of 481 bacterial ear pathogens were isolated from deep ear swab specimens of patients who came to Nini hospital clinical laboratory in Tripoli, North Lebanon. Culture, identification and antibiotic susceptibility of suspected isolates were carried out through conventional tests. API identification and serotyping were performed according to standard protocols proposed by the Référentiel en Microbiologie Médicale and the recommendations of the European Committee on Antimicrobial Susceptibility Testing.

Results: Out of 481, non-Enterobacteriaceae Gram negative rods were predominant (36.4\%) followed by Staphylococcus aureus (24.8\%), Enterobacteriace ae (16.8\%), Haemophilus influenzae (10\%), $\beta$-hemolytic streptococci (6.2\%), Streptococcus pneumoniae (5.4\%) and Moraxella catarrhalis (0.4\%). Susceptibility testing showed the prevalence rate of methicillin-resistant S. aureus was $18.5 \%$ and of penicillin-non-susceptible pneumococci was 30.8\%. Enterobacteriaceae and $H$. influenzae had susceptibilities of $18.5 \%$ and $80 \%$ to ampicillin, respectively. $P$. aeruginosa susceptibility to piperacillin-tazobactam and imipenem were very low, with $9.4 \%$ and $6.6 \%$, respectively. Overall, $H$. influenzae and S. pyogenes isolates were also among the more susceptible isolates to antibiotics.
Monzer Hamze', Marwan Osman', Hassan Mallat ${ }^{1}$, Marcel Achkar ${ }^{2}$

1 Laboratoire Microbiologie Santé et Environnement (LMSE), Ecole Doctorale des Sciences et de Technologie, Faculté de Santé Publique, Université Libanaise, Tripoli, Lebanon.

2 Clinical Laboratory, Nini Hospital, Tripoli, Lebanon

Corresponding author:

\section{Prof. Monzer Hamze}

झםmhamze@monzerhamze.com 
Conclusion: This study revealed widely different antibiotic resistance rates of bacterial ear pathogens among the examined patients in Tripoli, North Lebanon. These findings provide useful information to physicians to select the proper antibiotic for treatment of ear infections in North Lebanon. Also, allow health authorities to develop effective program to combat antibiotic resistance in Lebanon.

Keywords: Bacterial ear pathogens, Antibiotic susceptibility, Pseudomonas aeruginosa, Staphylococcus aureus, Haemophilus influenzae, Lebanon

\section{Introduction}

Ear infection is one of the most common illness which can be extremely painful because of inflammation and fluid buildup in the ear [1,2]. Its illness can affect the ear canal, the eardrum, or the middle ear. Ear infections are mostly observed in babies and young children, although it can occur in people of any age. Most children will have had at least one acute ear infection episode before three years of age. The main symptoms are ear pain, feeling unwell, fullness in the ear, hearing loss, ringing in the ear, discharge from the ear, nausea, vomiting and vertigo. Symptoms may follow a respiratory infection such as the common cold [1,2]. In addition, acute otitis externa (AOE), also known as 'swimmer's ear', is an inflammation or infection of external auditory canal, the auricle, or both which found often in adults[3]. However, otitis media with effusion (OME) is defined as a buildup of fluid in the middle ear but without symptoms and signs of infection, but this fluid can become occasionally infected, leading to acute otitis media (AOM). Numerous etiology of OME were described including allergies, irritants, previous respiratory infections, drinking while laying on your back and changes in air pressure $[2,3]$.

Both features of AOE and AOM can be painful. They are often caused by bacteria, but can also be caused by viruses. Although the etiological diagnosis is rarely discovered, bacterial infections are the most common cause of $\mathrm{AOE}$ and AOM [3]. Analgesics and fever-reducing drugs are the main treatment but also antibiotics are prescribed by clinicians for the cure of ear infections. The clinicians' decision will consider several factors for an ear infection such as age, illness severity, certainty a bacterial infection is present, and options for follow-up [4]. According to these factors, the decision will be either treat with antibiotics or waited a few days before prescribing antibiotics. Ear infections usually clear up on their own within a few days, and serious complications are rare. It has been noted that when an ear infection is caused by a virus, antibiotics will not help to get better and may even cause harm in both children and adults [4]. Nevertheless, ear infections are a leading cause for antibiotic prescriptions.

In Lebanon, numerous recent studies reported an increasing high rates of resistant bacteria isolates from clinical and commensal sources to most antimicrobials [5-21]. However, few data about the bacterial ear pathogens in Lebanon is available. For this reason, this investigation aimed to determine the occurrence of pathogens causing ear infections and its antibiotic susceptibility patterns in Tripoli, North Lebanon during the period of 7 years. 


\section{Material and methods}

This study was conducted at clinical microbiology laboratory of Nini hospital in Tripoli, North Lebanon over the period from January 2009 to December 2015. Deep ear swab specimens were obtained by clinicians from both ears of 463 patients ( 235 males and 228 females, ranging in age from 1 month to 85 years, with a mean age of 20 years) with presenting ear illness symptoms. All collected samples were transported immediately using Amies agar gel (Oxoid $^{\circledR}$, United Kingdom) to the microbiology laboratory.

Culture of specimens was performed according to standard protocols proposed by the Référentiel en Microbiologie Médicale (REMIC) using four different media including Columbia blood agar, Columbia CNA blood agar with 5\% sheep blood, Drigalski and Chocolate agar with bacitracin [22]. The identification of Enterobacteriaceae, non-Enterobacteriaceae Gram negative rods and Haemophilus spp. was carried out through the use of API-20E, API20NE and API-NH (bioMérieux ${ }^{\circledR}$ - France), respectively. The identification of $\beta$-hemolytic streptococci belonging to Lancefield groups $A, C$, and $G$ was performed by agglutination techniques (Bio-Rad ${ }^{\circledR}$, France). The detection of $\alpha$-hemolytic $S$. pneumoniae was carried out using the test of optochin susceptibility and latex agglutination tests (Bio-Rad ${ }^{\circledR}$, France). The identification of $S$. aureus was realized using catalase test and Pastorex ${ }^{\mathrm{TM}}$ Staph Plus kit (Bio-Rad ${ }^{\circledR}$, France).

The antibiotic susceptibility testing was performed by disk diffusion method on Mueller Hinton agar for S. aureus, Enterobacteriaceae and non-Enterobacteriaceae Gram negative rods (Bio-Rad ${ }^{\circledR}$, France), and on Mueller Hinton agar supplemented with $5 \%$ blood and $20 \mathrm{mg} / \mathrm{l} \beta$-NAD (MHF) for $H$. influenza, M. catarrhalis , S. pneumoniae and $\beta$-hemolytic streptococci according to the recommendations of the European Committee on Antimicrobial Susceptibility Testing (EUCAST).
Statistical analyses were performed with GraphPad Prism 6.0 (GraphPad Software Inc., San Diego, CA) using the Fisher's exact test to explore the association between bacterial infections and age of patients ( $\leq 10$ years and $>11$ years). The general significance level was set at a P-value below 0.05 .

\section{Results}

A total of 481 non-duplicated isolates were recovered from patient's specimens. Table 1 shows the distribution of isolates based on age of patients. Out of 481, non-Enterobacteriaceae Gram negative rods were the most frequently isolates (175/481; $36.4 \%)$ followed, by S. aureus (119/481; 24.8\%), Enterobacteriaceae (81/481; 16.8\%), H. influenzae (48/481; 10\%), $\beta$-hemolytic streptococci (30/481; $6.2 \%)$, S. pneumoniae $(26 / 481 ; 5.4 \%)$ and $M$. catarrhalis (2/481; 0.4\%).

Furthermore, approximately half of infected patients were children aged $\leq 10$ years old (236/481; $49 \%)$. H. influenzae (47/48; 98\%), S. pneumoniae (25/26; 96\%) and S. pyogenes (20/24; 83\%) were almost present in ear infection of this children group (Table 1).

The majority of cases occurred mostly during the winter season (158/481; 32.8\%) followed by spring season (126/481; 26.2\%) and fall season (110/481; $22.9 \%)$. However, the lowest number of cases was found in summer season (87/481; 18.1\%) (Figure 1). The results of antimicrobial susceptibility tests of all tested isolates are presented in Tables 2-4.

\section{Discussion}

According to our laboratory records, the majority of ear infection cases were due to $P$. aeruginosa, $S$. aureus, $H$. influenzae and $S$. pneumoniae with an average number of 19.4, 17, 6.9 and 3.7 cases per year over the last 7 years, respectively. $H$. influenzae, 
Table 1. Distribution of bacterial ear pathogens strains according to age of patients.

\begin{tabular}{|c|c|c|c|c|c|c|c|c|}
\hline \multirow[b]{2}{*}{ Age of patients } & \multicolumn{8}{|c|}{ Number of strains } \\
\hline & {$[0 ; 10]$} & {$[11 ; 20]$} & {$[21 ; 30]$} & {$[31 ; 40]$} & {$[41 ; 50]$} & {$[51 ; 60]$} & {$[61 ; 90]$} & Total \\
\hline$P$. aeruginosa & 49 & 29 & 10 & 9 & 12 & 17 & 10 & 136 \\
\hline Pseudomonas spp. & 6 & 8 & 3 & 1 & 1 & 1 & 0 & 20 \\
\hline Alcaligenes spp. & 4 & 2 & 5 & 1 & 1 & 1 & 0 & 14 \\
\hline Acinetobacter baumannii & 1 & 0 & 2 & 1 & 0 & 1 & 0 & 5 \\
\hline E. coli & 8 & 6 & 1 & 0 & 3 & 2 & 4 & 24 \\
\hline Proteus spp. & 7 & 6 & 1 & 2 & 0 & 2 & 1 & 19 \\
\hline Enterobacter spp. & 4 & 8 & 2 & 0 & 0 & 0 & 0 & 14 \\
\hline Klebsiella pneumoniae & 0 & 3 & 1 & 1 & 2 & 2 & 2 & 11 \\
\hline Citrobacter spp. & 0 & 4 & 0 & 0 & 0 & 1 & 0 & 5 \\
\hline Morganella morganii & 3 & 1 & 0 & 0 & 0 & 0 & 1 & 5 \\
\hline Providencia spp. & 1 & 2 & 0 & 0 & 0 & 0 & 0 & 3 \\
\hline H. influenzae & 47 & 1 & 0 & 0 & 0 & 0 & 0 & 48 \\
\hline M. catarrhalis & 2 & 0 & 0 & 0 & 0 & 0 & 0 & 2 \\
\hline S. aureus & 54 & 16 & 11 & 9 & 10 & 10 & 9 & 119 \\
\hline S. pneumoniae & 25 & 0 & 0 & 0 & 0 & 1 & 0 & 26 \\
\hline S. pyogenes & 20 & 2 & 1 & 1 & 0 & 0 & 0 & 24 \\
\hline Group C \& group G streptococci & 5 & 0 & 0 & 0 & 0 & 1 & 0 & 6 \\
\hline Total & 236 & 88 & 37 & 25 & 29 & 39 & 27 & 481 \\
\hline
\end{tabular}

S. pneumoniae and S. pyogenes infections were significantly predominant ( $p$-value $<0.001)$ in children aged less than 10 years. These three bacteria remain a leading cause of serious illness among babies and young children worldwide and are a frequent cause of ear infections [23]. However, P. aeruginosa was significantly prevalent in patients aged more than 10 years ( $p$-value $<0.001)$. P. aeruginosa ear infections are more prevalent in older population and often more difficult to treat [24]. No significant difference was found concerning the distribution of other reported bacteria species.

Otherwise, although ear infections occurred all year round, they were more common during the winter season when people spend more time in close contact indoors, children attending daycare and climate become colder.

This study confirms the wide range rates of an- tibiotic resistance among the majority of bacterial ear pathogens isolates in Tripoli, North Lebanon. Regarding $P$. aeruginosa, several Lebanese investigation showed the emergence of multidrug resistance strains. Al Bayssari et al. [25] reported the emergence of $P$. aeruginosa producing IMP-15 and VIM-2 carbapenemases and the disruption of the oprD gene. Moreover, Chamoun et al. [5] showed a trend of increasing resistance of antibiotics in Lebanon between 2011 and 2013, with the highest resistance being found to imipenem (27.2\%) followed by aztreonam (23.7\%) and ciprofloxacin (22.7\%). Another report showed mean resistant rates of $8.7 \%$ to imipenem, $13 \%$ to aztreonam and $8.7 \%$ to ciprofloxacin [19]. In our study, P. aeruginosa resistance to aztreonam and ciprofloxacin was $16.3 \%$ and $10.3 \%$, respectively, and within range of the respective rates reported previously. A slight decrease 


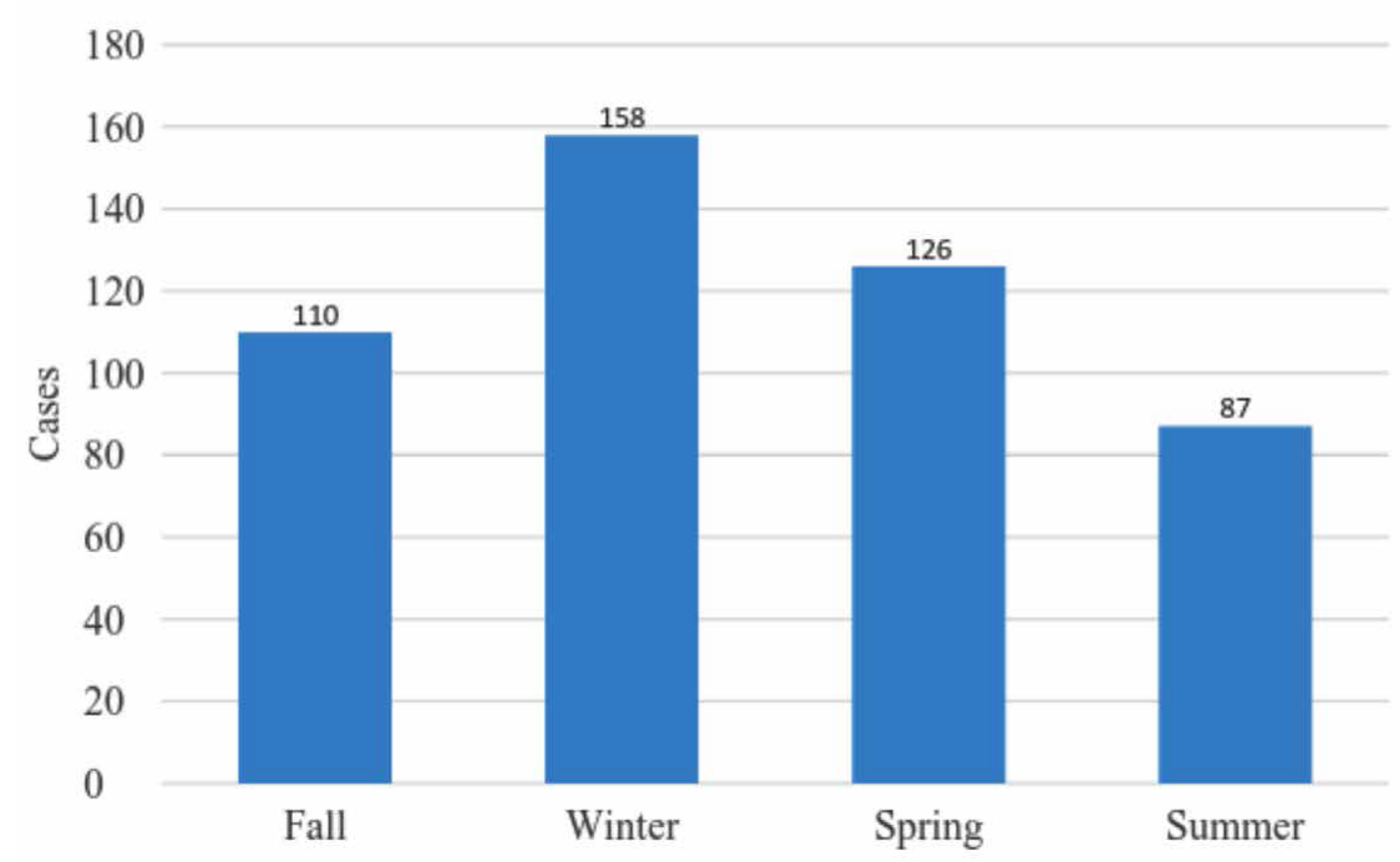

Figure 1. The seasonal distribution of ear infection cases in Lebanese patients.

in carbapenem resistance (6.6\%) was observed in the present study, while susceptibility to ticarcillin and ticarcillin-clavulanate was maintained at around $80 \%$ and to piperacillin and piperacillin-tazobactam at around $85 \%$.

Concerning $H$. influenzae, antibiotic resistance is more diverse and widespread than is commonly expected. $H$. influenzae isolates in our study revealed no-resistance to amoxicillin-clavulanate, cephalosporins, gentamicin, rifampicin and chloramphenicol. However, we note an emergence of resistance to kanamycin (2\%), fluoroquinolones $(3.4 \%)$, and tetracycline $(4.2 \%)$. Higher resistant rate of $\mathrm{H}$. influenzae was found against ampicillin (20\%). No BLNAR isolates were found which suggest that all ampicillin-resistant bacteria were producer of $\beta$-lactamase. Two recent studies conducted in Tripoli, North Lebanon described that all $\beta$-lactamase producing $H$. influenzae were TEM-1, which is the most frequent resistance mechanism reported for this species $[18,26]$.
Among the Enterobacteriaceae, E. coli was the predominant species. Various previous studies conducted in Lebanon showed a high prevalence of extended-spectrum beta-lactamases (ESBL)-producing E. coli with a mean rate of $20 \%[7,15]$ to $32 \%$ [5]. In addition, several reports described the emergence of carbapenemase-producing $E$. coli isolates, particularly OXA-48 [class D $\beta$-lactamases] [13,15,27-29]. In the present study, ESBL-producing E. coli was in the range of the previous reports since ertapenem, imipenem and meropenem resistance rates were about $6 \%, 0 \%$ and $0 \%$, respectively. Ciprofloxacin resistance was about $30 \%$, which is lower than that lately reported in the nationwide study [5], but in the range of that recently reported in Tripoli, North Lebanon $[7,15,21]$.

S. aureus is a major pathogen for both hospital and community-acquired infections. Of the 119 isolated strains in our study, 21 (18\%) MRSA. The high rate of MRSA observed in our study may result that $S$. aureus ear infections is becoming more difficult to treat. A 
Table 2. Percentage of antibiotic susceptibility of major Enterobacteriaceae isolates.

\begin{tabular}{|c|c|c|c|c|c|}
\hline & $\begin{array}{l}\text { E. coli } \\
\begin{array}{c}\mathrm{N}=24 \\
(\%)\end{array}\end{array}$ & $\begin{array}{l}\text { Proteus spp. } \\
\qquad \begin{array}{l}\mathrm{N}=19 \\
(\%)\end{array}\end{array}$ & $\begin{array}{l}\text { Enterobacter spp. } \\
\qquad \begin{array}{l}\mathrm{N}=14 \\
(\%)\end{array}\end{array}$ & $\begin{array}{l}\text { Klebsiella pneumoniae } \\
\qquad \begin{array}{c}\mathrm{N}=11 \\
(\%)\end{array}\end{array}$ & $\begin{array}{l}\text { Enterobacteriaceae* } \\
\qquad \begin{array}{c}\text { Total } N=81 \\
(\%)\end{array}\end{array}$ \\
\hline AMP & 20.8 & 47.4 & 0 & 0 & 18.5 \\
\hline AMC & 70.8 & 89.5 & 0 & 81.8 & 59.3 \\
\hline TIC & 37.5 & 57.9 & 92.9 & 0 & 50.6 \\
\hline TCC & 79.2 & 94.7 & 92.9 & 81.8 & 88.9 \\
\hline PIP & 37.5 & 57.9 & 92.9 & 0 & 50.6 \\
\hline PPT & 94.1 & 100 & 92.9 & 81.8 & 96.6 \\
\hline CFX & 58.3 & 57.9 & 0 & 81.8 & 46.9 \\
\hline CXM & 70.8 & 89.5 & 71.4 & 81.8 & 75.3 \\
\hline FOX & 83.3 & 100 & 0 & 90.9 & 76.5 \\
\hline CFM & 79.2 & 89.5 & 92.9 & 81.8 & 86.4 \\
\hline CTX & 79.2 & 89.5 & 92.9 & 81.8 & 87.7 \\
\hline CAZ & 79.2 & 89.5 & 92.9 & 81.8 & 87.7 \\
\hline FEP & 79.2 & 89.5 & 100 & 81.8 & 88.9 \\
\hline ATM & 79.2 & 89.5 & 92.9 & 81.8 & 87.7 \\
\hline ERT & 94.1 & 100 & 100 & 87.5 & 94.8 \\
\hline IMP & 100 & 78.9 & 85.7 & 90.9 & 88.9 \\
\hline MEM & 100 & 100 & 91.7 & 87.5 & 94.8 \\
\hline GMN & 66.7 & 78.9 & 100 & 81.8 & 81.5 \\
\hline TMN & 60.9 & 84.2 & 85.7 & 81.8 & 76.2 \\
\hline NET & 75 & 78.9 & 92.9 & 81.8 & 84.0 \\
\hline AKN & 95.8 & 100 & 100 & 100 & 98.8 \\
\hline OFX & 66.7 & 73.7 & 85.7 & 72.7 & 72.8 \\
\hline CIP & 70.8 & 78.6 & 92.9 & 72.7 & 76.5 \\
\hline TET & 58.3 & 0 & 57.1 & 70 & 46.2 \\
\hline MNO & 66.7 & 0 & 57.1 & 80 & 51.2 \\
\hline TGC & 95.8 & 0 & 85.7 & 90.9 & 77.8 \\
\hline CS & 100 & 0 & 100 & 100 & 65.4 \\
\hline FSF & 100 & 89.5 & 78.6 & 63.6 & 85.2 \\
\hline SXT & 58.3 & 57.9 & 92.9 & 72.7 & 69.1 \\
\hline
\end{tabular}

AMP, ampicillin $(10 \mu \mathrm{g})$; AMC, amoxicillin/clavulanate $(20 / 10 \mu \mathrm{g})$; TIC, ticarcillin $(75 \mu \mathrm{g})$; TCC, ticarcillin/clavulanate (75/10 $\mu \mathrm{g})$; PIP, piperacillin $(30 \mu \mathrm{g})$; PPT, piperacillin/tazobactam $(30 / 6 \mu \mathrm{g})$; ATM, aztreonam $(30 \mu \mathrm{g})$; IMP, imipenem $(10 \mu \mathrm{g})$; MEM, meropenem $(10$ $\mu \mathrm{g})$; ERT, ertapenem $(10 \mu \mathrm{g})$; CFX, cefalexin $(30 \mu \mathrm{g})$; CXM, cefuroxime $(30 \mu \mathrm{g})$; FOX, cefoxitin (30 $\mu \mathrm{g})$; CFM, cefixim $(5 \mu \mathrm{g})$; CTX, cefotaxime $(5 \mu \mathrm{g})$; FEP, cefepime $(30 \mu \mathrm{g})$; CAZ, ceftazidime $(30 \mu \mathrm{g})$; GMN, gentamicin $(10 \mu \mathrm{g})$; TMN, tobramycin (10 $\mu \mathrm{g})$; AKN, amikacin $(30 \mu \mathrm{g})$; NET, netilmicin $(10 \mu \mathrm{g})$; OFX, ofloxacin $(5 \mu \mathrm{g})$; CIP, ciprofloxacin $(5 \mu \mathrm{g})$; TET, tetracycline $(30 \mu \mathrm{g}) ; \mathrm{MNO}, \mathrm{minocycline}(30 \mu \mathrm{g})$; TGC, tigecycline $(15 \mu \mathrm{g}) ; \mathrm{CS}$, colistin $(50 \mu \mathrm{g}) ; \mathrm{FSF}$, fosfomycin $(200 \mu \mathrm{g}) ; \mathrm{SXT}$, trimethoprim/sulfamethoxazole $(1,25 / 23,75 \mu \mathrm{g})$.

*Enterobacteriaceae isolates include 24 E. coli, 19 Proteus spp., 14 Enterobacter spp., 11 K. pneumoniae, 5 Citrobacter spp., 5 Morganella morganii and 3 Providencia spp. 
Table 3. Percentage of antibiotic susceptibility of major non-Enterobacteriaceae Gram negative rods isolates.

\begin{tabular}{|c|c|c|c|c|}
\hline & $\begin{array}{l}\text { P. aeruginosa } \\
\qquad \begin{array}{c}\mathrm{N}=136 \\
(\%)\end{array}\end{array}$ & $\begin{array}{l}\text { Pseudomonas spp. } \\
\qquad \begin{array}{c}\mathrm{N}=20 \\
(\%)\end{array}\end{array}$ & $\begin{array}{l}\text { Alcaligenes spp. } \\
\qquad \begin{array}{c}\mathrm{N}=14 \\
(\%)\end{array}\end{array}$ & $\begin{array}{l}\text { Acinetobacter baumanni } \\
\qquad \begin{array}{l}\mathrm{N}=5 \\
(\%)\end{array}\end{array}$ \\
\hline TIC & 79.4 & 88.9 & 100 & 100 \\
\hline TCC & 80.9 & 90 & 100 & 80 \\
\hline PIP & 85.3 & 95 & 100 & 100 \\
\hline PPT & 90.6 & 100 & 100 & 100 \\
\hline CAZ & 91.9 & 85 & 85.7 & 20 \\
\hline FEP & 89 & 60 & 64.3 & 100 \\
\hline ATM & 83.7 & 50 & 21.4 & 0 \\
\hline IMP & 93.4 & 85 & 92.9 & 100 \\
\hline MEM & 97.6 & 100 & 100 & 100 \\
\hline GMN & 79.4 & 65 & 35.7 & 80 \\
\hline TMN & 88.2 & 60 & 35.7 & 80 \\
\hline NET & 79.1 & 60 & 42.9 & 100 \\
\hline AKN & 89.7 & 70 & 42.9 & 100 \\
\hline OFX & 64.7 & 60 & 35.7 & 80 \\
\hline CIP & 89.7 & 65 & 57.1 & 80 \\
\hline CS & 100 & 90 & 85.7 & 100 \\
\hline FSF & 68.4 & 45 & 21.4 & 0 \\
\hline
\end{tabular}

recent nationwide study revealed an increase in the prevalence of MRSA in Lebanese hospitals [5]. This prevalence was two times higher than that reported in healthy schoolchildren in the same region [30]. In addition, the study found that $S$. aureus isolates are still susceptible to vancomycin, teicoplanin and linezolid.

With regard to Streptococcus group, S. pneumoniae was the predominant species followed by S. pyogenes. Of the 26 S. pneumoniae isolates, $30.8 \%$ were penicillin non-susceptible S. pneumoniae (PNSP), and 34.6\% were resistant to both erythromycin and cotrimoxazole. A national prospective study reported that resistance rates to penicillin, erythromycin and cotrimoxazole were 17.4\%,
29.3\% and 54\%, respectively [31]. However, higher level of resistance to penicillin (53.8\%), erythromycin (41.3\%) and cotrimoxazole (56.7\%) was reported in another nationwide retrospective survey [5]. However, all S. pneumoniae isolates were susceptible to vancomycin, teicoplanin, linezolid, pristinamycin, tigecycline, gentamicin, streptomycin and fluoroquinolones. Penicillin, erythromycin and cotrimoxazole high resistance in $S$. pneumoniae has been incriminated due to antibiotic misuse and overuse of these antibiotics in Lebanon, since all oral antibiotics are easily available over the counter. While S. pyogenes remained sensitive to the majority of antibiotics during the study period. 
Table 4. Percentage of antibiotic susceptibility of S. aureus, S. pneumoniae, S. pyogenes and H. influenzae.

\begin{tabular}{|c|c|c|c|c|}
\hline & $\begin{array}{c}\text { S. aureus } \\
\mathrm{N}=119 \\
(\%)\end{array}$ & $\begin{array}{c}\text { S. pneumoniae } \\
\begin{array}{c}\mathrm{N}=26 \\
(\%)\end{array}\end{array}$ & $\begin{array}{c}\text { S. pyogenes } \\
\mathrm{N}=24 \\
(\%)\end{array}$ & $\begin{array}{c}\text { H. influenzae } \\
\begin{array}{c}\mathrm{N}=48 \\
(\%)\end{array}\end{array}$ \\
\hline $\mathbf{P}$ & - & - & 100 & 80 \\
\hline AMP & - & - & - & 80 \\
\hline AMC & - & - & - & 100 \\
\hline OX & - & 69.2 & - & - \\
\hline FOX & 81.5 & - & - & - \\
\hline CFX & - & - & - & 100 \\
\hline CXM & - & - & - & 100 \\
\hline CTX & - & - & - & 100 \\
\hline VAN & 100 & 100 & 100 & - \\
\hline TEI & 100 & 100 & 100 & - \\
\hline$S$ & - & 100 & 100 & - \\
\hline KMN & 78.2 & - & - & - \\
\hline TMN & 89.1 & - & - & - \\
\hline GMN & 90.8 & 100 & 100 & - \\
\hline C & 93.3 & 100 & 100 & 100 \\
\hline TET & 94.1 & 76.9 & 87.5 & 95.8 \\
\hline MNO & 100 & - & - & - \\
\hline TGC & 100 & 100 & 100 & - \\
\hline$E$ & 85.7 & 65.4 & 95.8 & - \\
\hline$C D$ & 95.8 & 69.2 & 95.8 & - \\
\hline PTN & 100 & 100 & 100 & - \\
\hline LZD & 100 & 100 & 100 & - \\
\hline FUS & 79.8 & - & - & - \\
\hline NA & - & - & - & 93.1 \\
\hline OFX & - & - & - & 96.6 \\
\hline CIP & - & - & - & 96.6 \\
\hline LVX & 87.7 & 100 & 100 & - \\
\hline MOX & 87.7 & 100 & 100 & - \\
\hline RIF & 98.3 & 96.2 & 95.8 & 100 \\
\hline SXT & 95 & 65.4 & 45.8 & 64.6 \\
\hline FSF & 95.8 & - & - & - \\
\hline NOV & 82.8 & - & - & - \\
\hline
\end{tabular}

P, penicillin G (1 UI) ; AMP, ampicillin $(2 \mu \mathrm{g})$; AMC, amoxicillin/clavulanate $(2 / 1 \mu \mathrm{g}) ; C \mathrm{CF}$, cefalexin $(30 \mu \mathrm{g})$; CXM, cefuroxime $(30 \mu \mathrm{g})$; CTX, cefotaxime $(5 \mu \mathrm{g})$; OX, oxacillin $(1 \mu \mathrm{g})$; FOX, cefoxitin $(30 \mu \mathrm{g})$; S, streptomycin $(300 \mu \mathrm{g})$; KMN, kanamycin $(30 \mu \mathrm{g})$; TMN, tobramycin $(10 \mu \mathrm{g}), \mathrm{GMN}$, gentamicin $(10 \mu \mathrm{g}$ for $\mathrm{S}$. aureus and $500 \mu \mathrm{g}$ for Streptococcus spp.), C, Chloramphenicol (30 $\mu \mathrm{g}) ;$;ET, tetracycline $(30 \mu \mathrm{g})$ ; MNO, minocycline $(30 \mu \mathrm{g})$; TGC, tigecycline $(15 \mu \mathrm{g})$; E, erythromycin $(15 \mu \mathrm{g})$; CD, clindamycin $(2 \mu \mathrm{g})$; PTN, pristinamycin $(15 \mu \mathrm{g})$; LZD, linezolid $(10 \mu \mathrm{g})$; TEl, teicoplanin $(30 \mu \mathrm{g})$; VAN, vancomycin $(5 \mu \mathrm{g})$; FUS, fusidic acid (10 $\mu \mathrm{g}) ; \mathrm{NA}$, nalidixic acid (30 $\mu \mathrm{g}) ;$ OFX, ofloxacin (5 $\mu \mathrm{g})$ ; CIP, ciprofloxacin $(5 \mu \mathrm{g})$; LVX, levofloxacin $(5 \mu \mathrm{g})$; MOX, moxifloxacin $(5 \mu \mathrm{g})$; RIF, Rifampicin $(5 \mu \mathrm{g})$; SXT, trimethoprim/sulfamethoxazole $(1,25 / 23,75 \mu \mathrm{g})$; FSF, fosfomycin $(200 \mu \mathrm{g})$; NOV, novobiocin $(5 \mu \mathrm{g})$. 
In conclusion, this study indicates that the antibiotic resistance rates of pathogens causing ear infection are widely varied among bacterial isolates in Tripoli, North Lebanon. These findings are probably correlated with the high spread of counterfeit medicines and the misuse and overuse of antibiotics. Therefore, cultures and antibiotic susceptibility testing of bacterial ear pathogens are very important to determine bacterial causes and to guide appropriate treatment.

\section{References}

1. Rovers MM, Schilder AG, Zielhuis GA, Rosenfeld RM. Otitis media. Lancet. 2004;363(9407):465-73.

2. Hui CP, Canadian Paediatric Society ID, Immunization C. Acute otitis externa. Paediatrics \& child health. 2013;18(2):96-101.

3. Minovi A, Dazert S. Diseases of the middle ear in childhood. GMS Curr Top Otorhinolaryngol Head Neck Surg 2014;13:Doc11.

4. Qureishi A, Lee Y, Belfield K, Birchall JP, Daniel M. Update on otitis media - prevention and treatment. Infect Drug Resist 2014;7:15-24.

5. Chamoun K, Farah M, Araj G, Daoud Z, Moghnieh R, Salameh $P$, et al. Surveillance of antimicrobial resistance in Lebanese hospitals: retrospective nationwide compiled data. Int J Infect Dis. 2016;46:64-70.

6. Hamze M, Osman M, Achkar M, Mallat H, Dabboussi F. Alarming increase in prevalence of Neisseria gonorrhoeae infections associated with a high level of antibiotic resistance in Tripoli, Lebanon. Int J Antimicrob Agents. 2016.

7. Hamze M, Osman M, Mallat H, Achkar M. Antibiotic Susceptibility of Salmonella spp., Shigella spp. and enteropathogenic Escherichia coli strains isolated from diarrheic children in Tripoli, North Lebanon. IAJAA 2016;6(2:2).

8. Al Bayssari C, Dabboussi F, Hamze M, Rolain JM. Emergence of carbapenemase-producing Pseudomonas aeruginosa and Acinetobacter baumannii in livestock animals in Lebanon. J Antimicrob Chemother. 2015;70(3):950-1.

9. Rafei R, Hamze M, Pailhories H, Eveillard M, Marsollier L, JolyGuillou ML, et al. Extrahuman Epidemiology of Acinetobacter baumannii in Lebanon. Appl Environ Microbiol 2015;81(7):235967.

10. Rafei R, Pailhories H, Hamze M, Eveillard M, Mallat H, Dabboussi $\mathrm{F}$, et al. Molecular epidemiology of Acinetobacter baumannii in different hospitals in Tripoli, Lebanon using bla OXA-51-like sequence based typing. BMC Microbiol 2015;15(1):103.

11. Rafei R, Dabboussi F, Hamze M, Eveillard M, Lemarie $C$, Mallat $\mathrm{H}$, et al. First report of blaNDM-1-producing Acinetobacter baumannii isolated in Lebanon from civilians wounded during the Syrian war. Int J Infect Dis 2014;21:21-3.
12. El Ayoubi MD, Hamze M, Mallat H, Achkar M, Dabboussi F. Glycopeptide intermediate Staphylococcus aureus and prevalence of the luk-PV gene in clinical isolates, in Northern Lebanon. Medecine et maladies infectieuses 2014;44(5):223-8.

13.Beyrouthy R, Robin F, Dabboussi F, Mallat H, Hamze M, Bonnet R. Carbapenemase and virulence factors of Enterobacteriaceae in North Lebanon between 2008 and 2012: evolution via endemic spread of OXA-48. J Antimicrob Chemother 2014;69(10):2699-705.

14. Mognieh R, Rafei R, Husni-Samaha R, Hamze M. Genetic and antibiotic susceptibility profiles of drug-resistant Acinetobacter baumannii from various parts of Lebanon IAJAA 2014;4(1):1-9.

15. Amrieh S, Hamze M, Mallat $H$, Achkar M, Dabboussi F. Detection of Escherichia coli O157:H7 and 0104:H4 in patients with diarrhea in Northern Lebanon and characterization of fecal $E$. coli producing ESBL and carbapenemase genes. IAJAA 2014;4(3:4).

16. Dabboussi F, Allouche S, Mallat H, Hamze M. Prevalence of first-step mutants among levofloxacin-susceptible isolates of Streptococcus pneumoniae in north Lebanon. J Chemother 2013;25(6):328-31.

17. Salma R, Dabboussi F, Kassaa I, Khudary R, Hamze M. gyrA and parC mutations in quinolone-resistant clinical isolates of Pseudomonas aeruginosa from Nini Hospital in north Lebanon. J Infect Chemother 2013;19(1):77-81.

18. Kassaa I, Hamze M, Dabboussi F. Molecular Characterization and resistance of $H$. influenzae isolated from Nasopharynx of Students in North Lebanon. IAJAA 2012;2(1:5):1-6.

19. Hamze M, Mallat H, Dabbousi F, Achkar M. Antibiotic susceptibility and serotyping of clinical strains of Pseudomonas aeruginosa isolated in northern Lebanon. IAJAA 2012; 2(4:2):1-6.

20. Osman M, Al Nasbeh A, Rafei R, Mallat H, Achkar M, Dabbousi $\mathrm{F}$, et al. Characterization of resistance genes to macrolides, lincosamides and streptogramins (MLS) among clinical isolates of Staphylococcus aureus in North Lebanon. IAJAA 2015;5(4:3):1-8.

21. Tabbouche S, Al Khudary R, Beyrouthy R, Dabbousi F, Achkar $\mathrm{M}$, Mallat $\mathrm{H}$, et al. Detection of genes TEM, OXA, SHV and CTX-M in 73 clinical isolates of Escherichia coli producers of extended spectrum Beta-lactamases and determination of their susceptibility to antibiotics. IAJAA 2011;1:1-6.

22. SFM. Référentiel en Microbiologie Médicale (REMIC). 5ème édition ed. Paris: Société Française de Microbiologie; 2015.

23. Rodrigues F, Morales-Aza B, Turner KM, Sikora P, Gould K, Hinds J, et al. Multiple Streptococcus pneumoniae serotypes in aural discharge samples from children with acute otitis media with spontaneous otorrhea. J Clin Microbiol. 2013;51(10):3409-11.

24. Gellatly SL, Hancock RE. Pseudomonas aeruginosa: new insights into pathogenesis and host defenses. Pathog dis 2013;67(3):159-73.

25. Al Bayssari C, Diene SM, Loucif L, Gupta SK, Dabboussi F, Mallat $\mathrm{H}$, et al. Emergence of VIM-2 and IMP-15 carbapenemases and inactivation of oprD gene in carbapenem-resistantPseudomonas aeruginosa clinical isolates from Lebanon. Antimicrob Agents Chemother. 2014;58(8):4966-70.

26. Kassaa I, Hamze M, Dabboussi F, Mallat H, Achkar M, Hlais S. Prevalence of type b Haemophilus influenzae and antibiotic resistance in 52 clinical isolates in north Lebanon. East Mediterr Health J. 2014;19 Suppl 3:S105-10. 
27. Al Bayssari C, Olaitan AO, Dabboussi F, Hamze M, Rolain JM. Emergence of OXA-48-producing Escherichia coli clone ST38 in fowl. Antimicrob Agents Chemother 2015;59(1):745-6.

28. Beyrouthy R, Robin F, Cougnoux A, Dalmasso G, DarfeuilleMichaud A, Mallat $\mathrm{H}$, et al. Chromosome-mediated OXA-48 carbapenemase in highly virulent Escherichia coli. J Antimicrob Chemother 2013;68(7):1558-61.

29. Beyrouthy R, Robin F, Delmas J, Gibold L, Dalmasso G, Dabboussi $F$, et al. IS1R-mediated plasticity of IncL/M plasmids leads to the insertion of bla OXA-48 into the Escherichia coli Chromosome. Antimicrob Agents Chemother 2014;58(7):3785-90.

30. Beyrouthy R, Hamze M, Hleis S, Mallat H, Dabboussi F. PantonValentine leukocidin producing Staphylococcus aureus nasal carriage, in North-Lebanon. Medecine et maladies infectieuses 2013;43(9):386-90.

31. Hanna-Wakim R, Chehab H, Mahfouz I, Nassar F, Baroud M, Shehab $M$, et al. Epidemiologic characteristics, serotypes, and antimicrobial susceptibilities of invasive Streptococcus pneumoniae isolates in a nationwide surveillance study in Lebanon. Vaccine 2012;30 Suppl 6:G11-7.

\section{Comment on this article:}
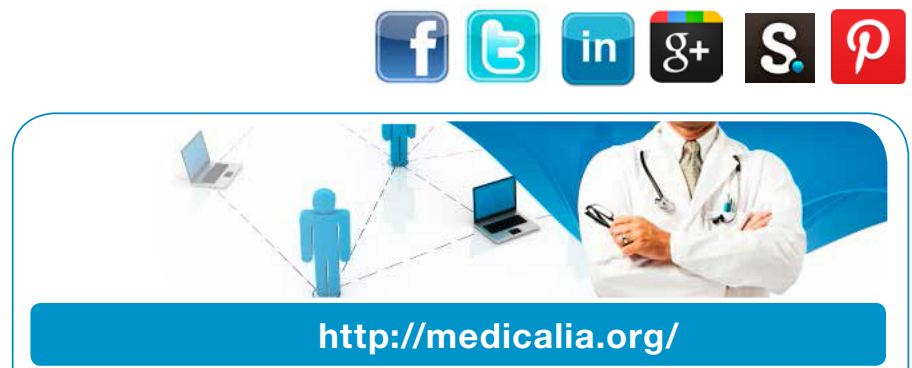

Where Doctors exchange clinical experiences, review their cases and share clinical knowledge. You can also access lots of medical publications for free. Join Now!

\section{Publish with iMedPub}

http://www.imed.pub

The Journal is an open access peer-reviewed journal that publishes scientific papers about all aspects of antimicrobials. The journal will publish original research articles, reviews, brief reports and case reports dealing with basic and clinical antibacterial agents, antiviral, antiprotozoals, antituberculuous, antifungal and antihelminthes agents.

All manuscripts must be prepared in English, and are subject to a rigorous and fair peer-review process. Accepted papers will immediately appear online.

The journal aims to advance the knowledge, attitude and the research of chemotherapy in the Arabic world in cooperation with international, national scientific and public societies as well as research centers with similar aims and objectives. 